University of Nebraska - Lincoln

DigitalCommons@University of Nebraska - Lincoln

1995

\title{
Foreshock sequence of the 1992 Landers, California, earthquake and its implications for earthquake nucleation
}

Douglas A. Dodge

Stanford University

Gregory C. Beroza

Stanford University

W. L. Ellsworth

U.S. Geological Survey

Follow this and additional works at: https://digitalcommons.unl.edu/usgsstaffpub

Part of the Earth Sciences Commons

Dodge, Douglas A.; Beroza, Gregory C.; and Ellsworth, W. L., "Foreshock sequence of the 1992 Landers, California, earthquake and its implications for earthquake nucleation" (1995). USGS Staff -- Published Research. 389.

https://digitalcommons.unl.edu/usgsstaffpub/389

This Article is brought to you for free and open access by the US Geological Survey at DigitalCommons@University of Nebraska - Lincoln. It has been accepted for inclusion in USGS Staff -- Published Research by an authorized administrator of DigitalCommons@University of Nebraska - Lincoln. 


\title{
Foreshock sequence of the 1992 Landers, California, earthquake and its implications for earthquake nucleation
}

\author{
Douglas A. Dodge and Gregory C. Beroza \\ Department of Geophysics, Stanford University, Stanford, California \\ W. L. Ellsworth \\ U.S. Geological Survey, Menlo Park, California
}

\begin{abstract}
The June 28, 1992, Landers, California, earthquake $\left(M_{W}=7.3\right)$ was preceded for about 7 hours by a foreshock sequence consisting of at least 28 events. In this study we examine the geometry and temporal development of the foreshocks using high-precision locations based on cross correlation of waveforms recorded at nearby stations. By aligning waveforms, rather than trying to obtain travel time picks for each event independently, we are able to improve the timing accuracy greatly and to make very accurate travel time picks even for emergent arrivals. We perform a joint relocation using the improved travel times and reduce the relative location errors to less than $100 \mathrm{~m}$ horizontally and less than $200 \mathrm{~m}$ vertically. With the improved locations the geometry of the foreshock sequence becomes clear. The Landers foreshocks occurred at a right step of about $500 \mathrm{~m}$ in the mainshock fault plane. The nucleation zone as defined by the foreshock sequence is southeast trending to the south and nearly north trending to the north of the right step. This geometry is confirmed by the focal mechanisms of the foreshock sequence, which are rightlateral and follow the trend as determined by the foreshock locations on the two straight segments of the fault, and are rotated clockwise for foreshocks that occur within the step. The extent of the foreshock sequence is approximately $1 \mathrm{~km}$ both vertically and horizontally. Modeling of the Coulomb stress changes due to all previous foreshocks indicates that the foreshocks probably did not trigger each other. This result is particularly clear for the $M_{w}=4.4$ immediate foreshock. Since stress transfer in the sequence appears not to have played a significant role in its development, we infer an underlying aseismic nucleation process, probably aseismic creep. Other studies have shown that earthquake nucleation may be controlled by fault zone irregularities. This appears to be true in the case of the Landers earthquake, although the size of the irregularity is so small that it is not detectable by standard location techniques.
\end{abstract}

\section{Introduction}

Perhaps the most convincing evidence that there is a nucleation stage before major earthquakes comes from observations of foreshocks. In a study of foreshock activity worldwide, Jones and Molnar [1979] found that $44 \%$ of $(M>7)$ earthquakes are preceded by foreshocks, where foreshocks are classified as any event greater than magnitude 4 that occurs within $100 \mathrm{~km}$ and within $\mathbf{4 0}$ days of the mainshock. Ishida and Kanamori [1978] classified as foreshocks five very similar events that occurred in the vicinity of the eventual hypocenter and within the 2 years before the 1971 San Fernando earthquake. These are examples of what $\mathbf{M o g i}$ [1985] refers to as "foreshocks in the broad sense." Foreshocks in the strict sense occur within a few hours to days of the mainshock, and within a few source dimensions of the mainshock. For instance, the $M_{L}=7.3$ Haicheng earthquake was preceded by about 500 earthquakes within 4 days of the mainshock. Of these, all with magnitude greater than 2 were within $5 \mathrm{~km}$ of the eventual mainshock epicenter [Zongjin et al., 1990].

Copyright 1995 by the American Geophysical Union.

Paper number 95JB00871.

$0148-0227 / 95 / 95 J B-00871 \$ 05.00$
Foreshocks are of particular interest because of their potential use in forecasting damaging earthquakes and because an understanding of foreshock behavior may help us understand how large earthquakes nucleate. The exact role of foreshocks in earthquake nucleation is not clear. Jones and Molnar [1979] attributed foreshocks to accelerating premonitory creep on the mainshock fault plane. This assumption was used by Ohnaka [1993] who linked the size of the nucleation zone to the region of foreshock activity. Jones [1984] found that the length of foreshock sequences is inversely proportional to depth, and concluded that this relation was due to increasing normal stress with depth. Since increased normal stress lengthens the time from creep onset to failure in theoretical nucleation models [Dieterich, 1978], a creep mechanism of foreshock generation was judged to be unlikely. Instead, Jones [1984] proposed a model of delayed multiple rupture with the time delay between ruptures, being the time required for static fatigue to bring adjacent patches to the failure point; however, Ohnaka [1992] maintains that earthquakes can nucleate without foreshocks near the base of the seismogenic crust, if the slip-weakening displacement is great enough.

In this paper we study the foreshock sequence of the 1992 $M_{W}=7.3$ Landers earthquake. The Landers foreshocks are interesting because they are well recorded and unambiguously associated with a major strike-slip earthquake. By detailed examination of this sequence, we are able to study some aspects of the nucleation process. Our basic data are seismograms 
recorded by the Southern California Seismic Network (SCSN). These are vertical component velocity seismograms recorded on $1 \mathrm{~Hz}$ sensors telemetered to the Southern California Earthquake Center, where they are digitized at 100 samples per second, analyzed, and eventually archived.

We relocate the foreshocks by the method of joint hypocenter determination (JHD) using relative arrival times determined by waveform cross correlation. With this method we obtain relative location uncertainties for most of the foreshocks that are less than $100 \mathrm{~m}$ in horizontal coordinates and less than $200 \mathrm{~m}$ in depth. We determine focal mechanisms for 14 of the largest foreshocks and the first of the two immediate foreshocks identified by Abercrombie and Mori [1994] to help confirm the geometry of the sequence and for use in modeling the static stress changes generated by the foreshock sequence. We estimate stress drops of several of the foreshocks using an empirical Green's function technique, and use these to constrain the static stress change modeling. We then estimate the static stress changes resolved on the foreshock fault planes due to the preceding foreshocks. Finally, we use the information obtained from our analysis to evaluate models of earthquake nucleation.

\section{The Landers Foreshock Sequence}

The $M_{w} 7.3$ Landers, California, earthquake was the largest earthquake in a sequence that began April 23 with the $M_{w}=6.1$ Joshua Tree earthquake. The Landers earthquake occurred on June 28, 1992, at 1157 UT, approximately 2 months after the Joshua Tree earthquake. The mainshock initiated with a $M w=4.4$ immediate foreshock [Abercrombie and Mori, 1994] before propagating $\sim 70 \mathrm{~km}$ along strike to the northwest [Cohee and Beroza, 1994]. The epicenter was about $30 \mathrm{~km}$ north-northwest of the Joshua Tree epicenter, and the Joshua Tree aftershock zone extended to within a few kilometers of the Landers epicenter (Figure 1). There was an unmistakable foreshock sequence for the Landers earthquake. It consisted of 27 events that occurred within 7 hours of the Landers mainshock and that were tightly clustered within about $1.5 \mathrm{~km}$ of the mainshock hypocenter [Hauksson et al., 1994]. There were an additional eight events that occurred between the date of the Joshua Tree mainshock (April 23) and June 28 and were located within $5 \mathrm{~km}$ of the Landers epicenter. These may be considered part of the foreshock sequence in a broader sense. The Landers foreshock sequence was the third of three earthquake swarms that occurred north of the Pinto Mountain fault during the Joshua Tree aftershock sequence. Each of these swarms was disconnected from the main group of aftershocks, and became active shortly after the Joshua Tree mainshock.

The first swarm was centered approximately $15 \mathrm{~km}$ eastsoutheast of the Landers mainshock epicenter, and approximately $28 \mathrm{~km}$ north of the Joshua Tree epicenter. It consisted of 88 events distributed over the 9-week interval between the Joshua Tree and Landers mainshocks. As shown in Figure 1, the swarm was adjacent to the southern end of the surface trace of a fault known to be active in quaternary time [Bortugno, 1986]. The second swarm was located midway between the first swarm and the immediate foreshock cluster, approximately on a line defined by the early north-south aftershocks of Joshua Tree. It was also located near the southern end of the surface trace of a fault known to be active in quaternary time [Bortugno, 1986]. This cluster consisted of 74 events, most of which occurred within a 5day period beginning 20 days before the Landers mainshock. The third swarm is the immediate Landers foreshock cluster that we analyze in this paper. It was located on the southern extension of the Johnson Valley fault that ruptured in the Landers mainshock. It is also approximately on the projection of the Joshua Tree mainshock rupture plane as determined by first motion data.

Figure 2 shows the time histories for the three clusters. Note that the eastern cluster displays typical swarmlike behavior with no dominant event in the sequence. The central cluster is dominated by a $M_{W}=4.4$ event which occurred 17 days before the Landers mainshock. Most of the remaining seismicity in that cluster could be described as aftershocks to the $M w=4.4$ event. In contrast to the first two clusters, the third cluster was nearly aseismic until the day of the mainshock.

\section{Data Analysis}

\section{Improvement of Foreshock Locations}

Figure 3 shows locations calculated for 27 of the immediate foreshocks to the Landers earthquake as listed in the SCSN catalog. The network locations define a diffuse cloud approximately $2 \mathrm{~km}$ in horizontal extent and about $3 \mathrm{~km}$ in vertical extent. About half of the foreshocks are located at a depth of less than one kilometer, and three events are located at the surface. Using these locations, it is difficult either to assess how close these events are to each other, or to discern any structure in the seismicity that would indicate the foreshocks are occurring on a single fault. Furthermore, the location of three events at the surface is a clear indication that the depths of these events are poorly constrained. Such errors are typical of network locations, and are due to a variety of factors including poor station distribution, inadequate velocity model, and inconsistent arrival time picks.

If only relative locations are required, as is often the case when studying clustered seismicity such as foreshocks, the problems with the velocity model can be minimized by using the arrival times to simultaneously estimate hypocenters, velocity model corrections, and station corrections. If the events are clustered in a small volume, the ray paths from all the events are virtually identical, and almost all the unmodeled velocity structure can be absorbed in the station corrections. We use the VELEST earthquake location program [Ellsworth, 1977; Roecker, 1981] to relocate the foreshocks in this study.

\section{S Wave Picks and Improved P Wave Picks By Waveform Cross Correlation}

Because the immediate Landers foreshocks are clustered within a small volume, and because foreshocks have been observed to have very similar waveforms [e.g., Ishida and Kanamori, 1978], we expected that we could use cross correlation techniques to improve the precision of the $P$ wave picks. Previously Poupinet et al., [1984] and Fremont and Malone [1987] used a frequency-domain cross correlation technique to calculate differential $\boldsymbol{P}$ wave arrival times precise to a few milliseconds for similar events recorded by regional earthquake networks. Fremont and Malone [1987] used differential times to relocate a set of explosions with a precision of about 20 meters. Deichmann and Garcia-Fernandez [1992] used time domain cross correlation to relocate microearthquakes with a precision of a few tens of meters. Dodge et al. [1993] used frequency domain cross correlation to relocate a cluster of microearthquakes recorded by the US Geological Survey (USGS) Calnet with a precision of a few tens of meters. The relocation procedures cited above are all master event procedures. With these procedures, a single event with clear arrivals that is similar 


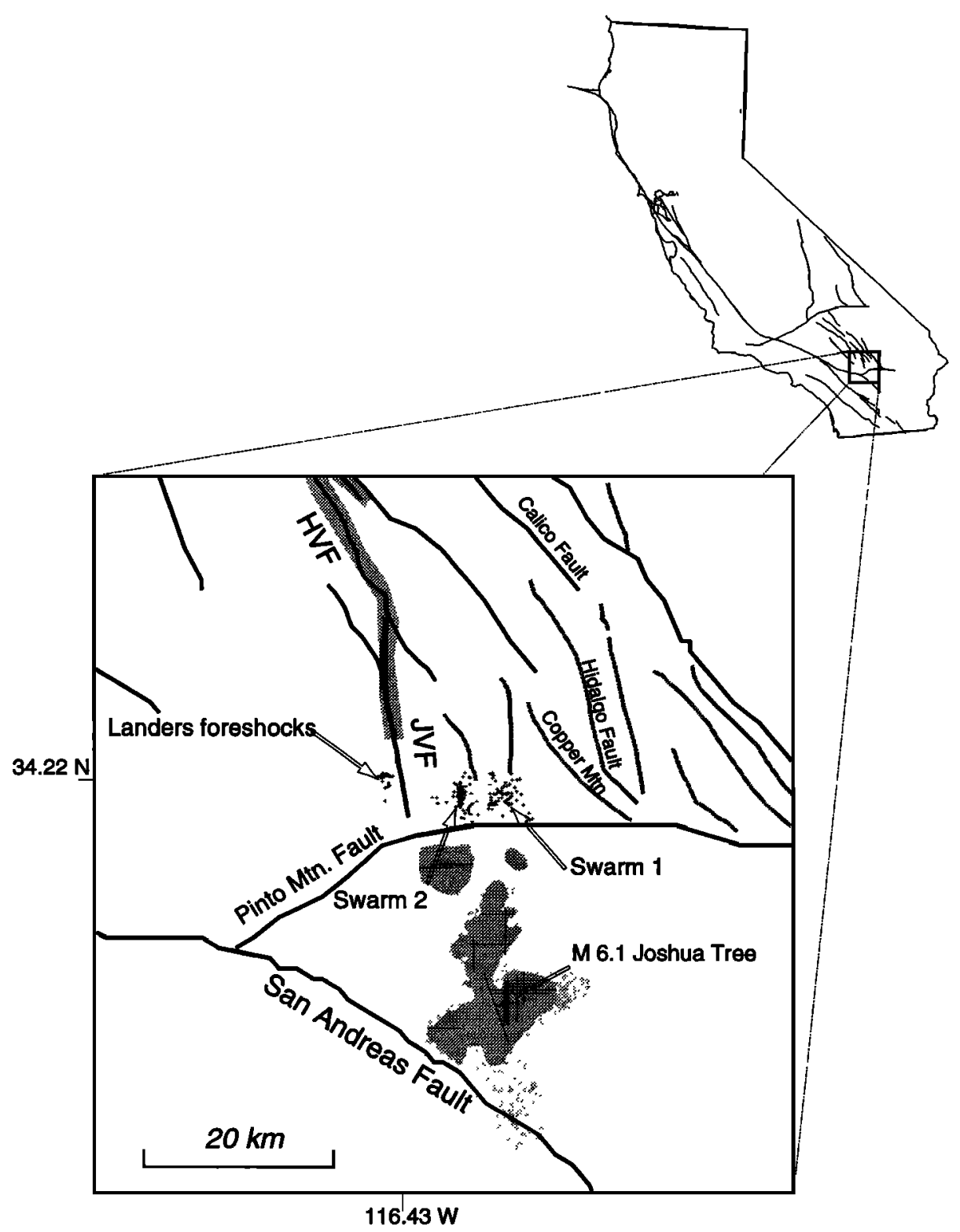

Figure 1. Base map centered on the Landers epicenter. The light gray regions south of the Pinto Mountain fault show the extent of aftershocks of the Joshua Tree earthquake. Just north of the Pinto Mountain fault are three swarms of preshocks to the Landers earthquake. The swarm which contains the immediate foreshocks to the Landers earthquake is just off the southern extension of the Johnson Valley fault (JVF). The fault segments which ruptured in the Landers earthquake are shown as heavy lines extending north along the JVF and the Homestead Valley fault (HVF).

to all the remaining events, is first located by conventional methods, and the remaining events are all relocated relative to the master. However, as we will show, the Landers foreshocks extend about $1700 \mathrm{~m}$ along strike and over a kilometer in depth. The foreshocks also do not lie on a single plane. Rather, they define a plane with a $500 \mathrm{~m}$ right step, and the earthquake focal mechanisms vary across the step. So, even though there are about 15 events within about $300 \mathrm{~m}$ of each other in the step, the focal mechanisms are slightly different, the waveforms are dissimilar, and there is no single event sufficiently similar to all the others to be used as a master event for cross correlation.

Our solution to this problem was to employ a technique developed by VanDecar and Crosson [1990] for determining relative arrival times of teleseisms recorded by a regional seismic network. This technique uses the cross correlations between all pairs of signals and a weighted least squares adjustment of the corresponding shifts to determine an optimum set of arrival time corrections and estimates of the errors in the resulting adjusted picks. The least squares weights are the maximum values of the inter channel cross correlation functions, so the corrections calculated for a given channel are influenced primarily by the channels most similar to the channel in question. Thus there is no requirement for a single event which is highly similar to all the other events.

At each station we begin with preliminary estimates of the $P$ wave and $S$ wave arrival times for all events and cross correlate each event against every other using windows centered around the estimated arrival. For each pair we determine the maximum 

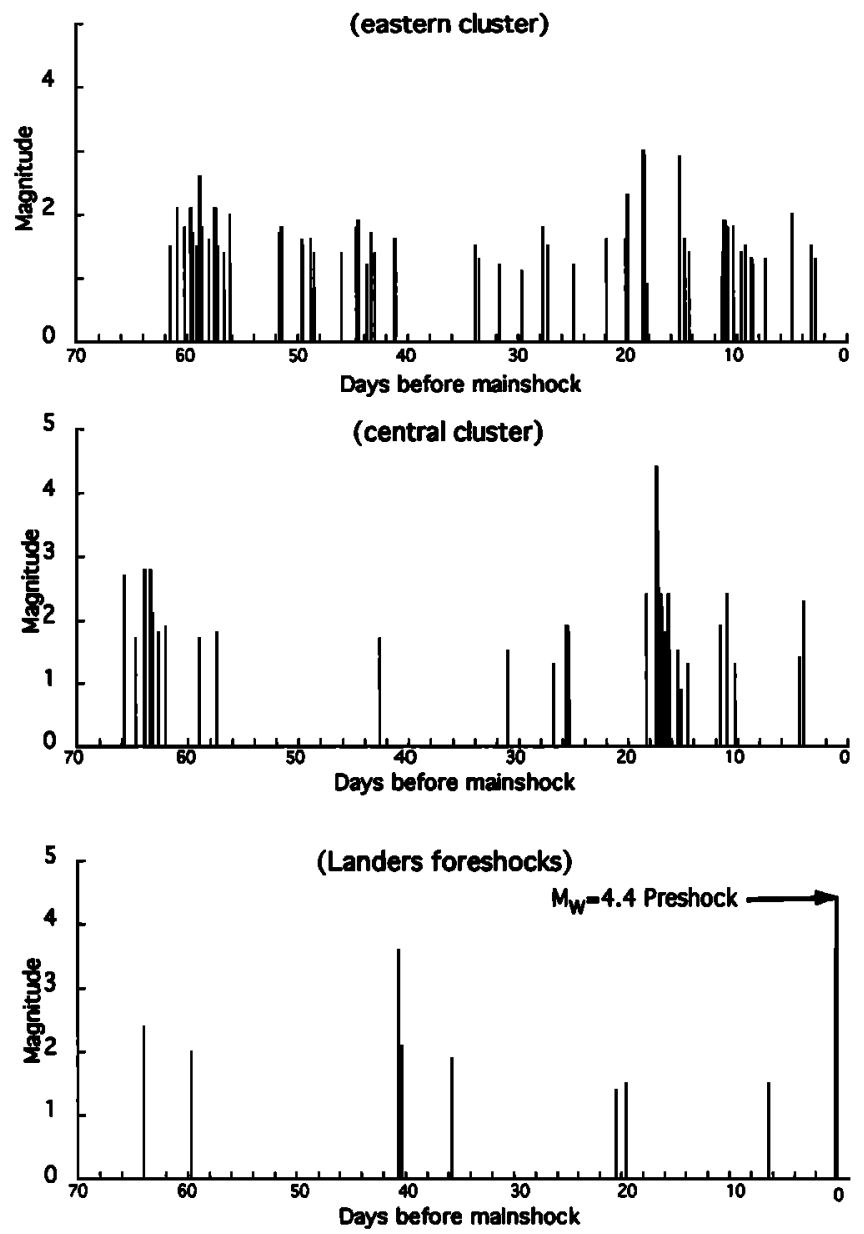

Figure 2. Time history of the three earthquake clusters near the Landers mainshock. The eastern cluster (farthest from epicenter) shows swarmlike behavior with no well-defined dominant event. The central cluster is dominated by a $M w=4.4$ event which has its own aftershock sequence. The cluster which includes the Landers foreshocks is nearly aseismic until the day of the mainshock.

and the shift corresponding to the maximum, and use this to construct a system of equations relating arrival time differences and cross correlation delays to a set of arrival time corrections. The system is solved by weighted least squares using a zero mean constraint on the arrival time corrections, and the arrival time corrections are then added to the estimated times. The error estimates for the improved picks are the standard deviations of the data residuals for each pick. See VanDecar and Crosson [1990] for details.

In most cases, only a subset of the events recorded at a given station are sufficiently similar to adjust this way. Accordingly, our implementation of this algorithm automatically removes events with mean cross correlation maxima less than a threshold value (usually 0.8 ). We also allow interactive removal of problematic traces. The removed traces are then either picked by hand if the onsets are clear, or else are not used. Figure 4 shows some examples of automatic picks.

The algorithm's success varies from station to station. For instance, at stations near the $\boldsymbol{P}$ wave nodes for most events, the similarity of the $P$ waves tends to be low and fewer than half of the events are automatically picked. However, the $S$ wave similarity tends to be higher at the $P$ wave nodes, so the lack of cross correlation-derived $\boldsymbol{P}$ wave picks may be compensated by an abundance of cross correlation derived $S$ wave picks. In fact, the algorithm is quite effective at picking $S$ waves. It was able to pick approximately $400 S$ wave arrivals (about one third of the total arrivals used to relocate the foreshocks). These $S$ wave picks proved essential in constraining the depths of the foreshocks, since with our velocity model, up going rays from the Landers hypocentral region occur at only three stations. It is well known [e.g., Roecker, 1981] that in the absence of $S$ wave readings, $P$ wave readings from both up going and down going rays are needed to control the trade-off between origin time and depth.

The foreshock relocation results we present later, and a comparison of the picks produced by our algorithm to those produced by network analysts suggest that a significant part of the improvement in source location quality due to cross correlation picking results from the removal of outliers in network picks. The picks produced by the network analysts are the result of examining a trace in isolation. There is always a
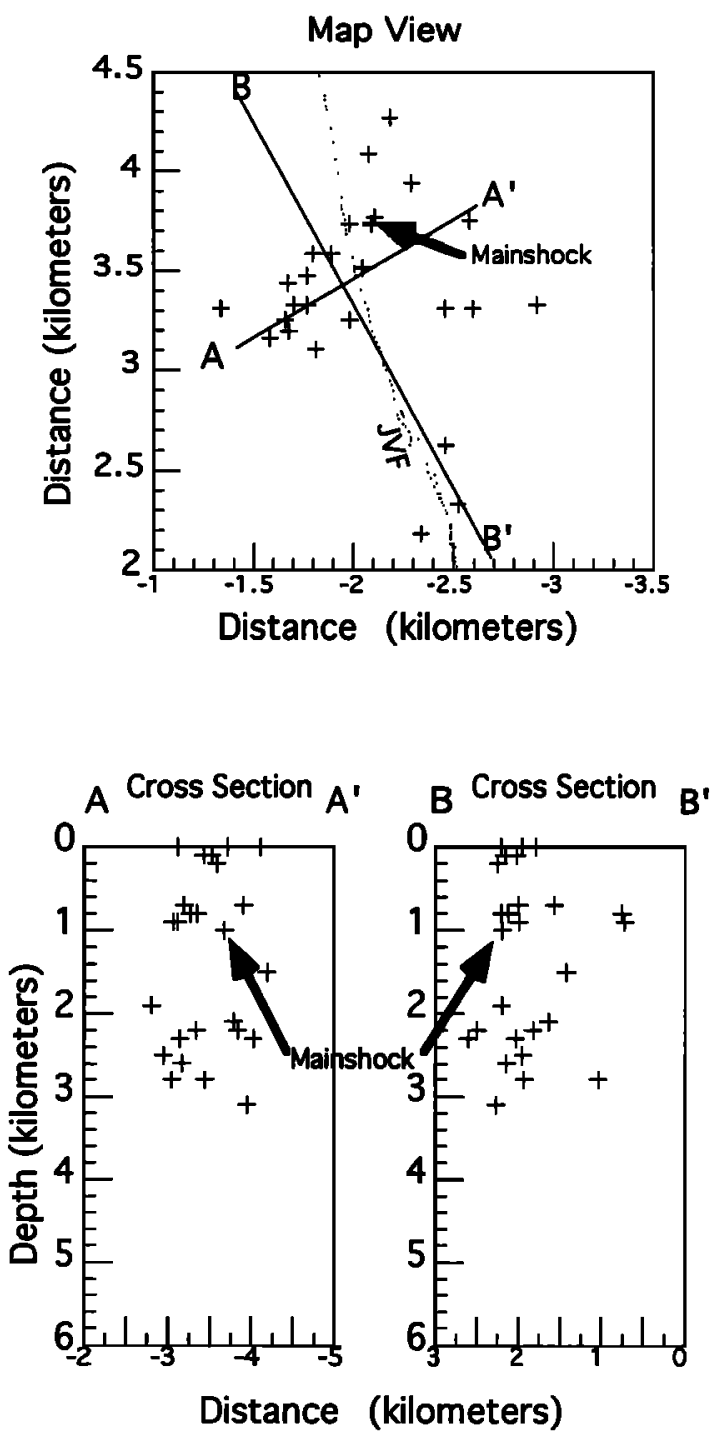

Figure 3. Locations of the immediate Landers foreshocks calculated by the Southern California Seismic Network. The top frame shows a map view of the events. The dotted line is the surface trace of the Johnson Valley fault. The lines A-A' and B-B' indicate the orientation of the two cross sections shown below. All distances are in kilometers. 

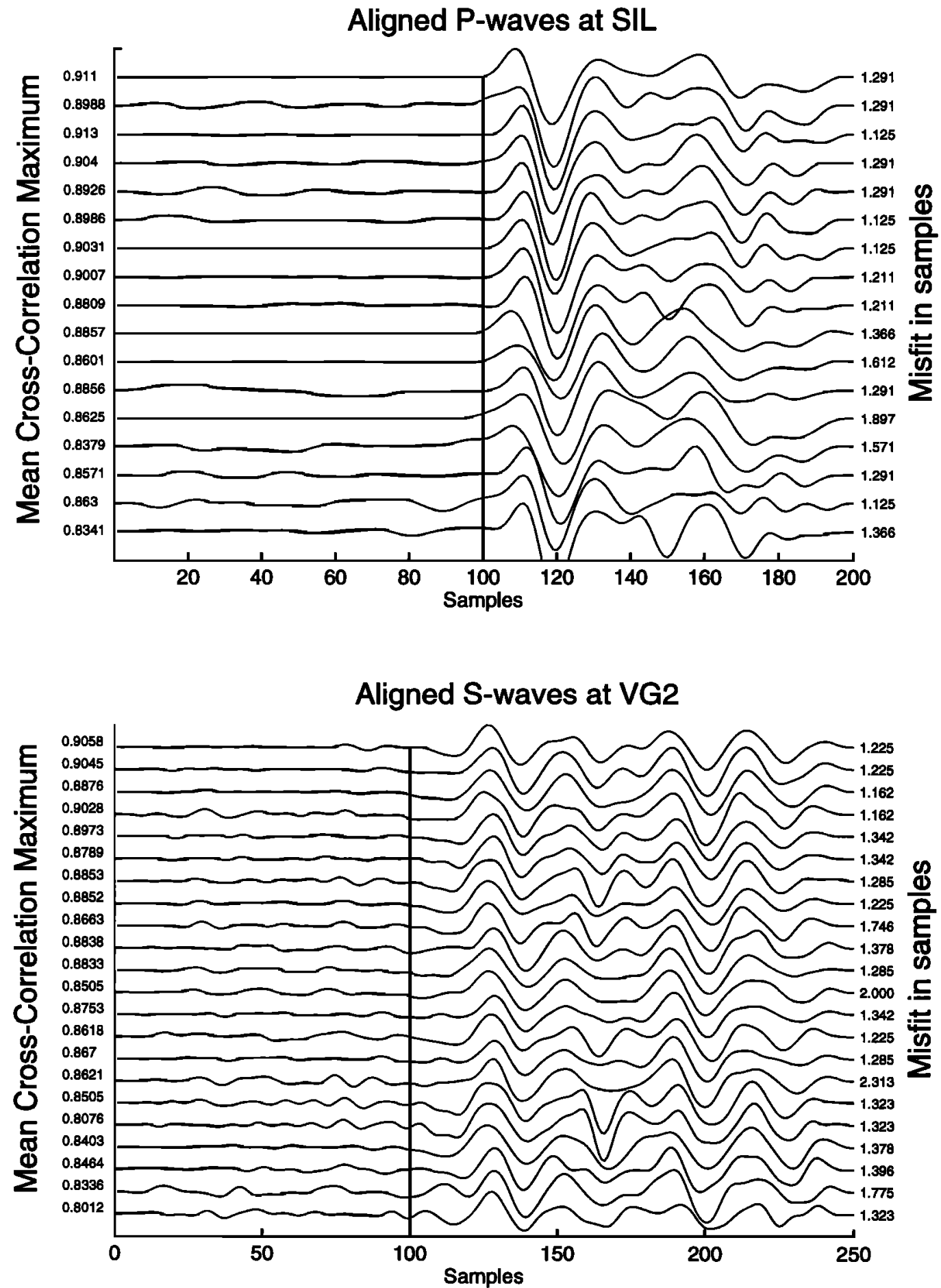

Figure 4. Examples of seismograms aligned by least squares adjustment of cross correlation-derived delays. The upper panel shows $2 \mathrm{~s}$ of $P$ waves sampled at 100 samples per second. The lower panel shows $2.5 \mathrm{~s}$ of $S$ waves sampled at 100 samples per second. The numbers on the left axes are the mean values of the cross-correlation maxima relative to all the other traces. The numbers on the right axes are the average values of the cross correlation delays relative to the other traces.

judgment made as to when the signal first appears in the noise. At very quiet sites, or for large events, the signal onset may be unambiguous. However, if the signal onset is emergent, or if there is significant noise, the picks can be seriously in error. Figure 5 shows the foreshock seismograms recorded at station CSP aligned by the automatic picker. The arrows on the plot show the location of picks determined by the network analysts. Note that for the two largest earthquakes (the $M_{L}=3.0$ and $M_{L}=2.9$ events) our picks and the analyst picks are in near agreement. The remaining picks differ by as much as $0.25 \mathrm{~s}$. The fourth and fifth seismograms, which are nearly identical, have analyst picks that differ by about $0.2 \mathrm{~s}$. 


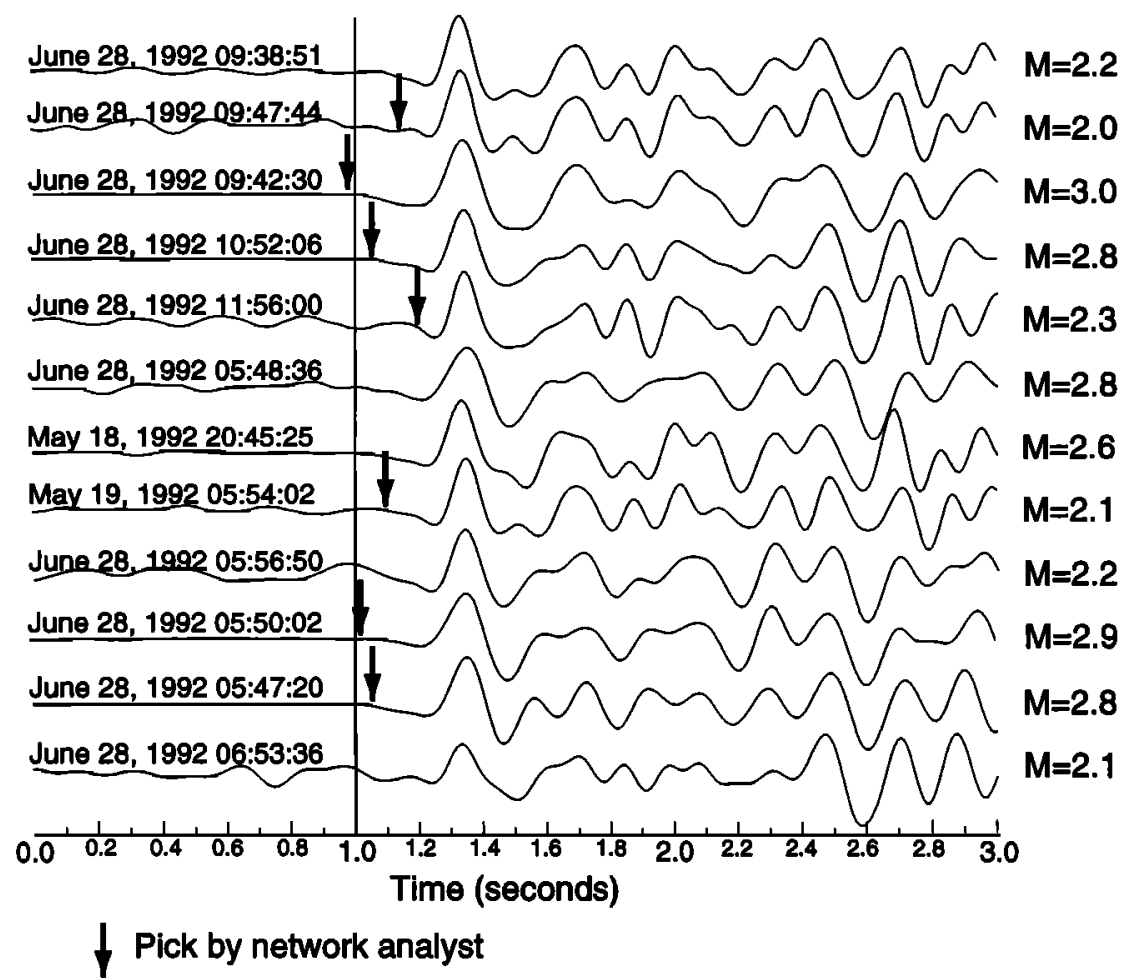

Figure 5. A comparison of $P$ wave picks made by waveform comparison to those made by network analysts. These seismograms are from a set of 15 recorded at station CSP approximately $85 \mathrm{~km}$ distant from the foreshock cluster. The seismograms are shown aligned on the picks determined by waveform cross correlation. The down going arrows show the location of picks made by network analysts. Traces with no arrows were not picked by analysts

\section{JHD Solutions Using Network Picks and Cross $=$ Correlation Picks}

We first relocated the foreshocks by JHD using picks obtained from the SCSN database. The starting $P$ wave velocity model was the Hauksson et al. [1994] model, and the starting $S$ wave model was the $P$ wave model scaled by $1 / \sqrt{3}$. We only used observations out to $130 \mathrm{~km}$ from the epicenter. This restriction was applied so that the set of observations associated with smaller events would be comparable to that associated with the larger events. We began with the 27 immediate foreshocks plus six earthquakes that occurred near the Landers hypocenter after the Joshua Tree earthquake and the mainshock. Of these, 11 either were separated from the main cluster by 2 or more kilometers, or else had solutions that did not converge in depth. The poorly constrained solutions all had azimuthal gaps of $180^{\circ}$ or more, and had observations at $\mathbf{1 5}$ or fewer stations. To avoid compromising the precision of the remaining hypocenter estimates, we removed these events. We then estimated hypocenters, station corrections, and model corrections, using the remaining events and the updated models and station corrections from the first inversion. The results of this relocation are shown in Figure 6a.

We determined improved arrival times by cross correlation for 28 events including the immediate foreshock and inverted these data starting with the previously obtained station corrections and model corrections. Three of the resulting hypocenters were poorly constrained, and these events were removed. The remaining events included all those previously located with network picks plus three events which did not converge with network picks. We inverted the data one more time for station and model corrections and then solved for the locations using the final model and station corrections. The results are shown in Figure $6 \mathrm{~b}$ and Table 1.

Although the inversion using the cross correlation times results in only a slight reduction in average travel time residuals $(0.039$ for network picks versus $\mathbf{0 . 0 3 4}$ for cross correlation picks), there are significant reductions in the relative solution uncertainties. The standard errors in horizontal coordinates for JHD with network picks average $107 \mathrm{~m}$. In depth they average $391 \mathrm{~m}$. By contrast, the standard errors for JHD with cross correlation times average $52 \mathrm{~m}$ in horizontal coordinates and $100 \mathrm{~m}$ in depth. Undoubtedly, the improvement in depth control is due to the large number of cross correlation $S$ wave picks. The reduction in horizontal uncertainty is probably due to the improved consistency of the $P$ wave picks. Table $1 \mathrm{~b}$ presents a more detailed comparison of the solution statistics.

The final hypocenters determined in this inversion are strongly clustered, both in map view and in depth. In particular, the vertical extent of the hypocenters is slightly over $1 \mathrm{~km}$, rather than the $\mathbf{4} \mathbf{~ k m}$ seen in the JHD solutions with network picks. The relocated epicenters clearly define a narrow band of seismicity with a right step of about $0.5 \mathrm{~km}$ near the northern end of the sequence. The trend of the seismicity is similar to that of the Johnson Valley fault. All but two of the foreshocks occur to the south of the immediate foreshock.

We calculated focal mechanisms for 15 of the largest foreshocks using the FPFIT program [Reasenberg and Oppenheimer, 1985]. These are shown on a map of the foreshock locations in Figure 7. The focal mechanisms were determined using 18 to 41 first-motion polarities. Nearly all the observations 
a) Relocations Using Network Picks
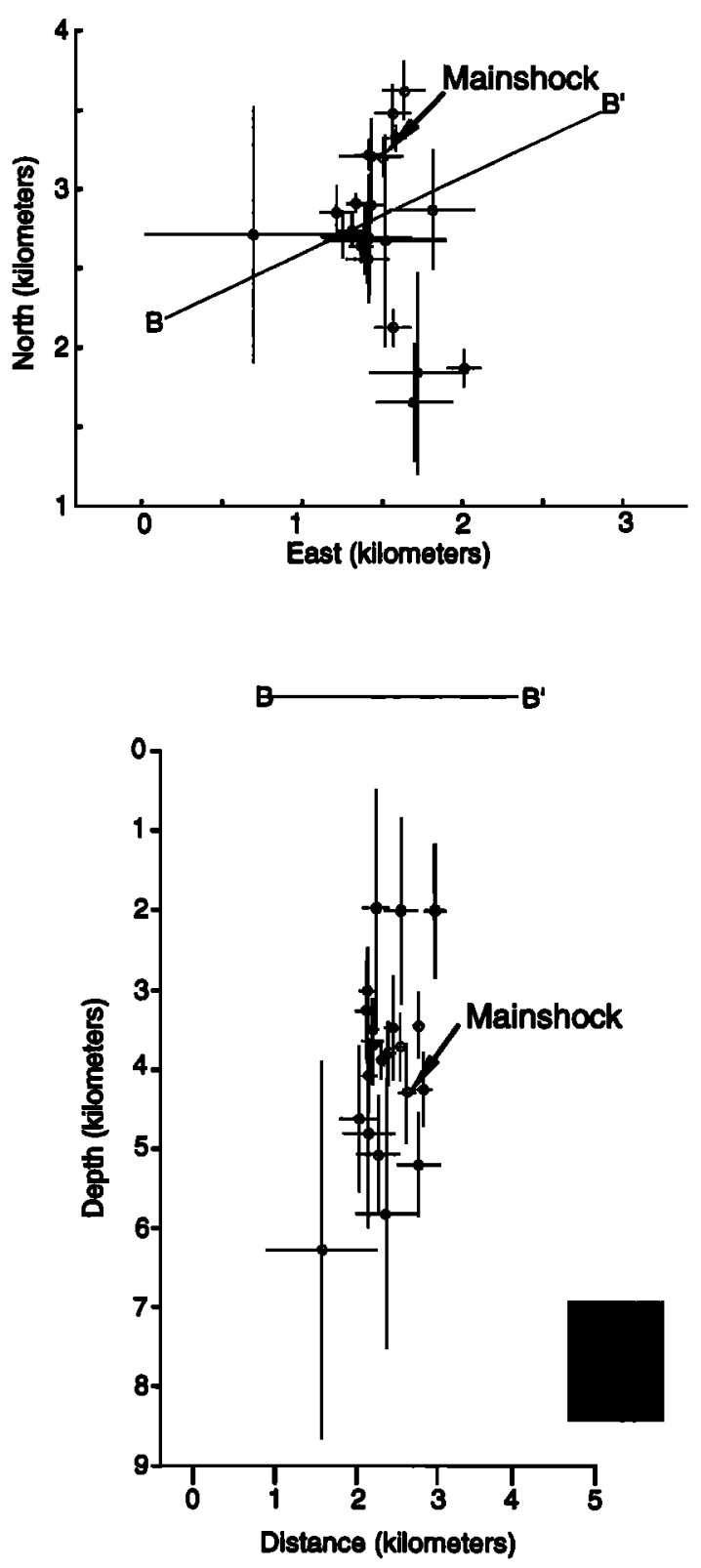

b) Relocations Using Improved Picks
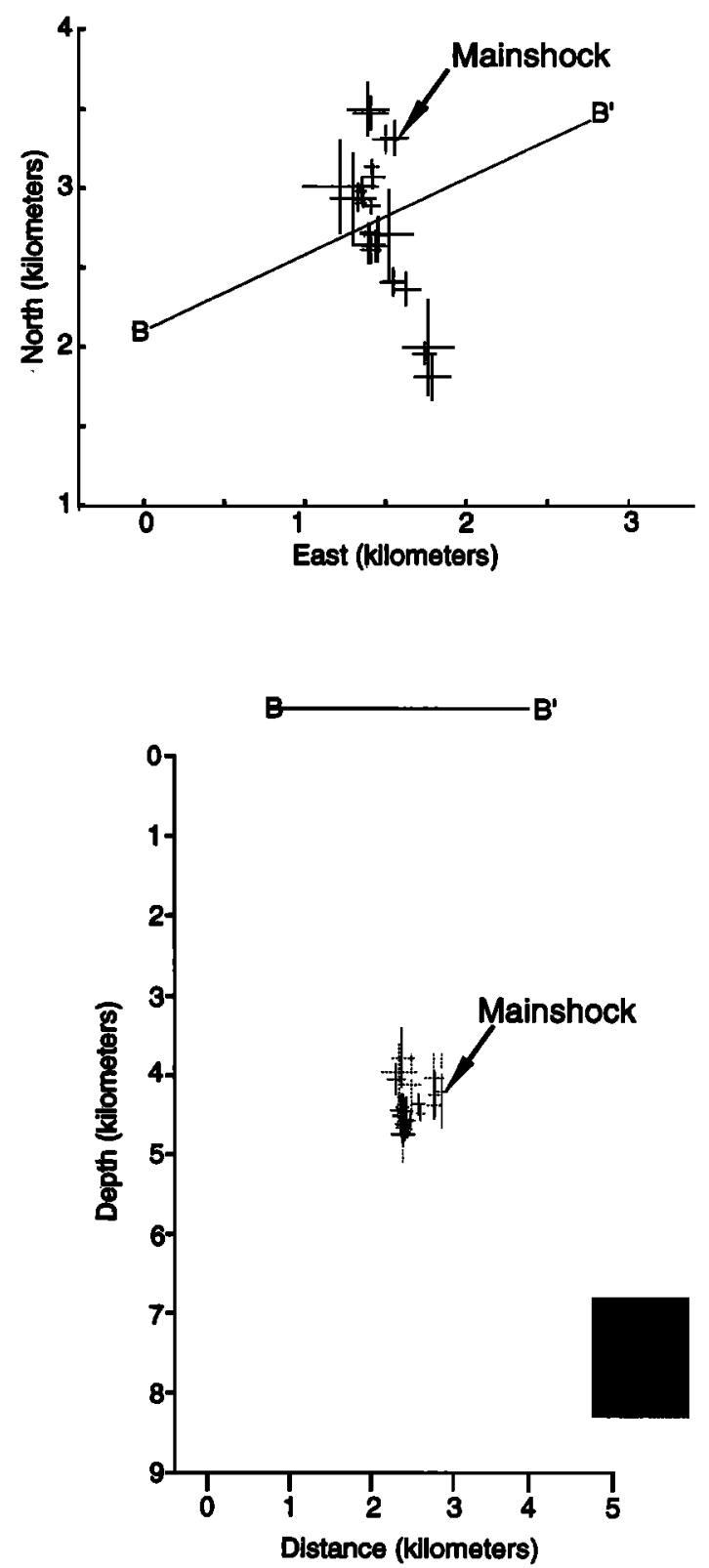

Figure 6. Relocated foreshocks in map and cross-sectional views. (a) The relocations made using JHD with network picks.and (b) the relocations made using JHD with $P$ and $S$ times determined by waveform cross correlation are shown. In both cases, the error bars are the $2 \sigma$ limits for the coordinates. (top) $A$ map view of the foreshocks is shown. (bottom) The cross sectional views A-A' defined on the map views of the epicenters are shown.

plot near the equator of the focal sphere, so the dips are not well constrained. The average dip uncertainty is $26^{\circ}$. These events are primarily right-lateral strike-slip with average uncertainties of only $6^{\circ}$ in strike. The focal mechanisms are remarkably consistent with the geometry determined from the foreshock relocations. The five events south of the jog have fault planes that strike $151^{\circ} \pm 3^{\circ}$. This is generally consistent with the strike of the seismicity south of the jog $\left(140^{\circ}\right.$ to $\left.145^{\circ}\right)$. The three events north of the jog have fault planes that strike $163^{\circ} \pm 6^{\circ}$, again consistent with the strike of the seismicity $\left(160^{\circ}\right)$. The strike of the seven events in the jog is $178^{\circ} \pm 4^{\circ}$, a clockwise rotation of about $20^{\circ}$ relative to the events outside the jog.

\section{Source Parameter Determination}

We determined stress drops for the larger foreshocks using the empirical Green's function technique of Mori and Frankel [1990]. For small earthquakes the comer frequency of the displacement spectrum may be controlled by site and propagation effects rather than by the earthquake source. A relatively uncorrupted estimate of the displacement spectrum may be obtained by using a much smaller, similar earthquake as an empirical Green's function to deconvolve the displacement spectrum from the spectrum of the larger earthquake [Mueller, 1985; Frankel and Kanamori,1983; Mori and Frankel, 1990]. 
Table 1a. Foreshock Locations

\begin{tabular}{|c|c|c|c|c|c|c|c|c|c|c|}
\hline Events & Group & CUSP ID & Date & Time UT & Latitude ${ }^{\circ} \mathrm{N}$ & Longitude ${ }^{\circ} \mathrm{W}$ & Depth & Magnitude & Number & RMS \\
\hline 1 & 1 & 2052770 & May 18,1992 & $2045: 25.61$ & 34.1868 & 116.4367 & 4.49 & 2.60 & 57 & 0.035 \\
\hline 2 & 1 & 2052827 & May 19,1992 & $0554: 02.50$ & 34.1909 & 116.4388 & 4.64 & 2.10 & 55 & 0.035 \\
\hline 3 & 1 & 2053369 & May 23, 1992 & $1803: 45.70$ & 34.1905 & 116.4379 & 4.53 & 1.90 & 38 & 0.042 \\
\hline 4 & 2 & 2056929 & June 28, 1992 & $0521: 30.59$ & 34.2005 & 116.4403 & 4.35 & 2.00 & 38 & 0.039 \\
\hline 5 & 2 & 2056931 & June 28, 1992 & $0547: 20.85$ & 34.1974 & 116.4403 & 4.45 & 2.80 & 77 & 0.029 \\
\hline 6 & 2 & 3031215 & June 28,1992 & $0548: 05.00$ & 34.1968 & 116.4402 & 4.34 & 2.80 & 67 & 0.037 \\
\hline 7 & 2 & 3031226 & June 28, 1992 & $0550: 02.63$ & 34.1935 & 116.4398 & 4.43 & 2.90 & 53 & 0.038 \\
\hline 8 & 2 & 2056932 & June 28, 1992 & $0554: 41.04$ & 34.1990 & 116.4393 & 4.22 & 3.60 & 51 & 0.030 \\
\hline 9 & 2 & 3031167 & June 28, 1992 & $0556: 50.39$ & 34.1929 & 116.4400 & 4.38 & 2.20 & 37 & 0.034 \\
\hline 10 & 2 & 3031046 & June 28,1992 & $0558: 38.46$ & 34.1963 & 116.4409 & 4.55 & 2.80 & 66 & 0.031 \\
\hline 11 & 2 & 2056934 & June 28, 1992 & $0600: 49.13$ & 34.1952 & 116.4403 & 4.55 & 2.90 & 48 & 0.024 \\
\hline 12 & 3 & 2056935 & June 28, 1992 & $0630: 00.19$ & 34.1855 & 116.4362 & 4.02 & 1.80 & 20 & 0.034 \\
\hline 13 & 3 & 2056937 & June 28, 1992 & $0652: 13.42$ & 34.2007 & 116.4405 & 4.01 & 1.80 & 21 & 0.037 \\
\hline 14 & 3 & 2056938 & June 28, 1992 & $0653: 36.88$ & 34.1956 & 116.4408 & 4.65 & 2.10 & 60 & 0.031 \\
\hline 15 & 4 & 2056953 & June 28,1992 & $0937: 29.61$ & 34.1937 & 116.4391 & 4.12 & 1.50 & 11 & 0.025 \\
\hline 16 & 4 & 2056954 & June 28, 1992 & 0938:51.16 & 34.1927 & 116.4403 & 4.48 & 2.20 & 58 & 0.037 \\
\hline 17 & 4 & 2056955 & June 28, 1992 & $0942: 30.53$ & 34.1937 & 116.4404 & 4.42 & 3.00 & 72 & 0.031 \\
\hline 18 & 4 & 3031227 & June 28,1992 & $0947: 29.24$ & 34.1871 & 116.4364 & 3.75 & 2.00 & 14 & 0.041 \\
\hline 19 & 4 & 2056956 & June 28, 1992 & 0947:44.38 & 34.1909 & 116.4388 & 4.58 & 2.20 & 48 & 0.035 \\
\hline 20 & 5 & 2056964 & June 28, 1992 & 1052:06.49 & 34.1960 & 116.4411 & 4.68 & 2.80 & 87 & 0.032 \\
\hline 21 & 5 & 2056965 & June 28, 1992 & $1056: 37.47$ & 34.1930 & 116.4405 & 4.41 & 1.90 & 19 & 0.025 \\
\hline 22 & 5 & 3031233 & June 28,1992 & $1057: 24.00$ & 34.1963 & 116.4424 & 3.93 & 1.60 & 16 & 0.049 \\
\hline 23 & 6 & 2056970 & June 28, 1992 & $1145: 39.37$ & 34.1956 & 116.4415 & 4.72 & 1.70 & 13 & 0.031 \\
\hline 24 & 6 & 2056971 & June 28, 1992 & $1156: 00.33$ & 34.1954 & 116.4412 & 4.70 & 2.30 & 75 & 0.031 \\
\hline 25 & 6 & 3031111 & June 28, 1992 & $1157: 34.07$ & 34.1990 & 116.4387 & 4.23 & 4.40 & 45 & 0.030 \\
\hline
\end{tabular}

Table 1b. Comparison of JHD with Network Picks and Cross - Correlation Picks

\begin{tabular}{lcc} 
& Network Picks & Cross-Correlation Picks \\
\hline Number of P observations & 679 & 762 \\
Number of S observations & 26 & 403 \\
Average observations per event & 31 & 47 \\
Average RMS, seconds & 0.039 & 0.034 \\
Average Gap & $95^{\circ}$ & $54^{\circ}$ \\
Average $\sigma_{\mathrm{x}}$, meters & 89 & 45 \\
Average $\sigma_{\mathrm{y}}$, meters & 124 & 60 \\
Average $\sigma_{\mathrm{z}}$, meters & 391 & 100 \\
\hline
\end{tabular}

JHD is joint hypocenter determination.

Mori and Frankel [1990] obtained successful deconvolutions for magnitude 3.4 to 4.4 earthquakes using Green's function events that were within $400 \mathrm{~m}$ of the event epicenters, and with magnitudes at least 1.3 units smaller than the event of interest. For these conditions they estimated an uncertainty of .02 seconds in the half widths of the deconvolved pulses.

We found three events of magnitude 1.8 to 2.0 that were within 400 to $500 \mathrm{~m}$ of most of the larger events, and used them to deconvolve displacement pulses at five stations within $100 \mathrm{~km}$ of the foreshock cluster. Because of the differences in focal mechanisms of the foreshocks, there is more $P$ waveform variation near the nodal planes than near the center of the quadrants. To increase the range of usable events, we used SCSN stations CSP and SIL, which are within the northwest compressional quadrant for all the foreshocks, and stations WWR, VG2, and KEE, which are well within the southwest dilatational quadrant for all the foreshocks. The distribution of stations was also chosen to look for azimuthal variations in the pulse widths that might indicate directivity. By using multiple stations and multiple Green's function events, we could also estimate the reliability of our deconvolutions.
We obtained 30 usable deconvolutions for the seven events listed in Table 2. Plots of the displacement pulses are shown in Figure 8. Most of the pulses show little evidence of complexity. The pulses for events $5,7,10$, and 20 are all single-peaked and symmetric. Some of the pulses for events 17 and 11 show multiple peaks; however, since these features vary significantly from deconvolution to deconvolution, they may be artifacts. The source time function for event 6 shows two distinct pulses on all three deconvolutions, so there may be two sub events in that rupture. There is no systematic variation in the source time functions. The sets of displacement pulses in Figure 8 are arranged so that the northern most stations are at the top of each set and the southern most stations are at the bottom. Since the fault planes strike approximately north-south, directivity effects would show up as a systematic variation in pulse width from top to bottom of each plot. There is a hint of variation in the plots for events 6 and 5 . However with only three stations for each event it is hard to be certain that the variation in pulse width is not due to some other factor. In fact, the stations at which we were able to calculate source time functions are not particularly well positioned to observe directivity-induced variations in the source 


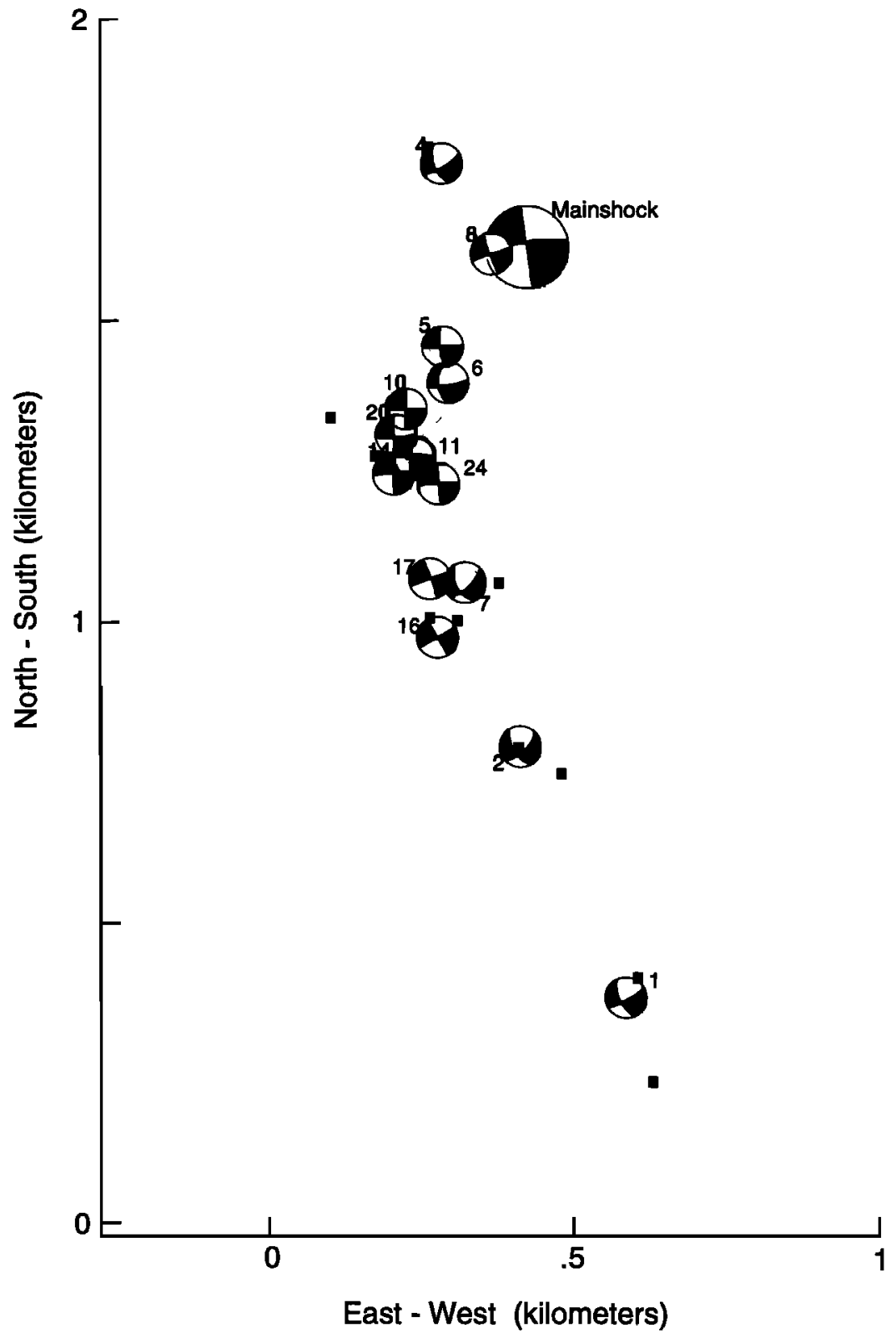

Figure 7. Fault plane solutions for 14 of the larger foreshocks and for the first of the two immediate foreshocks to the main rupture. Focal mechanisms were determined using the FPFIT program [Reasenberg and Oppenheimer, 1985]. The immediate foreshock (identified as Mainshock on the plot) symbol is shown larger than the other events, but otherwise, the symbol size is not proportional to magnitude.

Table 2. Determination of Source Parameters

\begin{tabular}{cccccc}
\hline Event & CUSP ID & $\mathrm{M}_{0} * 10^{13} \mathrm{Nm}$ & $\tau_{1 / 2}, \mathrm{~s}$ & $\mathrm{a}, \mathrm{km}$ & $\Delta \sigma, \mathrm{MPa}$ \\
\hline 5 & 2056931 & 1.51 & $.0717 \pm .0216$ & $.326(.235-.417)$ & $0.19(0.51-0.09)$ \\
11 & 2056934 & 2.51 & $.0406 \pm .0166$ & $.175(.103-.246)$ & $0.94(4.57-0.34)$ \\
17 & 2056955 & 3.55 & $.0549 \pm .0147$ & $.214(.157-.271)$ & $0.68(1.74-0.33)$ \\
20 & 2056964 & 1.51 & $.0313 \pm .0033$ & $.135(.121-.149)$ & $1.43(1.99-1.06)$ \\
10 & 3031046 & 1.51 & $.0429 \pm .0122$ & $.188(.134-.241)$ & $1.47(4.00-0.69)$ \\
6 & 3031215 & 1.51 & $.0548 \pm .0208$ & $.234(.145-.323)$ & $0.28(1.19-0.11)$ \\
7 & 3031226 & 2.51 & $.0873 \pm .0184$ & $.321(.254-.389)$ & $0.15(0.31-0.09)$ \\
\hline
\end{tabular}



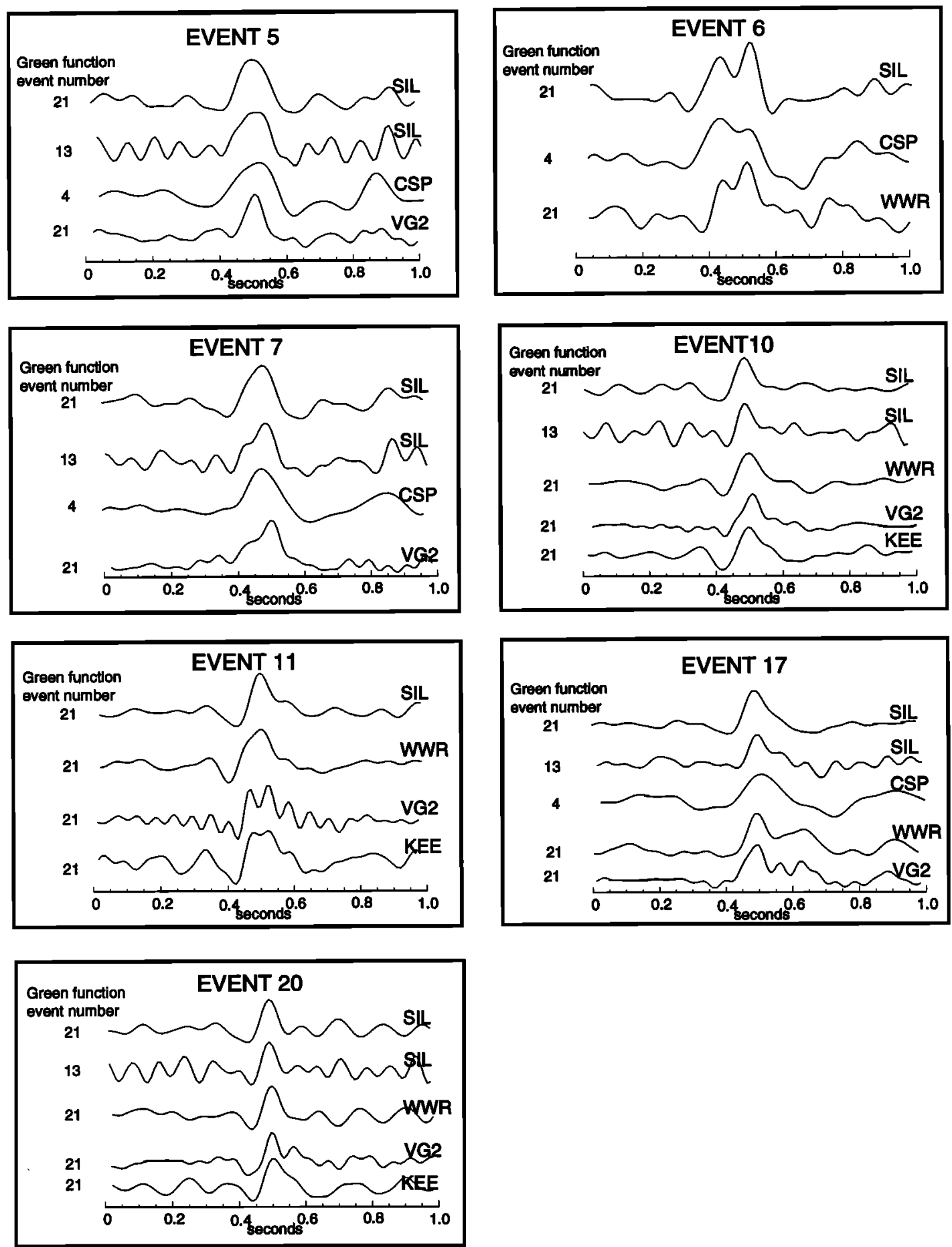

Figure 8. Source time functions determined for seven of the largest foreshocks. The displacement pulses were determined by deconvolving Green's function events from the displacement seismograms of the larger events. Deconvolutions were calculated using three different Green's function events at up to five stations. Each frame in this figure shows all the successful deconvolutions for one of the large foreshocks.

time functions particularly if rupture is bilateral, since they span only about $90^{\circ}$ of azimuth relative to the sources.

We estimated the stress drops for the seven events following Mori and Frankel [1990]. The source radius, $a$, was calculated using an expression from Boatwright [1980] for a circular source,

$$
a=\frac{\tau_{\underline{k}} v}{1-v \sin \theta / c\left(x_{0}\right)},
$$

where $\tau_{Y_{2}}$ is the risetime of the displacement pulse, $v$ is the rupture velocity (assumed to be $\left.3.4 \mathrm{kms}^{-1}\right), c\left(x_{0}\right)$ is the local $P$ wave velocity $\left(6.1 \mathrm{kms}^{-1}\right)$ and $\theta$ is the angle between the fault normal and the $P$ wave takeoff direction. Then the static stress drop was calculated using an expression from Brune [1970],

$$
\Delta \sigma=\frac{7}{16} \frac{M_{0}}{a^{3}} .
$$


For $M_{0}$ we converted the SCSN magnitudes to moments in Newton meters using the expression

$$
\log M_{0}=1.5 M+9.05 \text {. }
$$

The risetime we used was a simple average of individual risetime measurements for all deconvolutions of each event. Because the stress drop depends on the cube of the source radius, estimates of the stress drop are very sensitive to errors in the pulse width. Thus although our nominal values for stress drop for the seven events range from $0.15 \mathrm{MPa}$ to $1.47 \mathrm{MPa}$, the range of stress drops corresponding to a $1 \sigma$ variation in risetime is 0.09 to 4.57 $\mathrm{MPa}$.

All the events with stress drop estimates are in the fault jog. Although these stress drops might not be appropriate for events well to the north or south of the jog, those more distant events have a very small effect on the static stress changes that we calculate for events in the jog, and with the exception of event 1 are not used.

\section{Spatiotemporal Development of the Foreshock Sequence}

For purposes of discussion we have divided the foreshocks into six groups. The group 1 foreshocks began in the hypocentral region weeks before the mainshock, and the mechanical relation of these early foreshocks to the eventual mainshock is unclear. Figure 9 shows the three early occurring foreshocks to be farther south than most of the other foreshocks. Their only obvious connection to the rest of the sequence is that they occurred on (apparently) a fault plane common to most of the other foreshocks, and the existence of later foreshocks as far south as event 1.

Group 2 contained the bulk of the seismic moment for the foreshock sequence. It appears to have involved failure in the jog between the two fault segments and on the northern segment. The sequence began with a $M_{L}=2.0$ earthquake near the eventual mainshock hypocenter at 0521:31 UT. After about $26 \mathrm{~min}$ of quiescence, a series of seven $M_{L}=2.2$ to $M_{L}=3.6$ earthquakes occurred within about $12 \mathrm{~min}$. In addition to these seven earthquakes, other earthquakes occurred but could not be located because their onsets were buried in the coda waves from previous events. The first three of the located events ruptured southward and across the jog. Shortly after, the largest event of the sequence, a $M_{L}=3.6$ event occurred just below and overlapping the eventual $M_{w}=4.4$ immediate foreshock. The sequence completed with three $M_{L}=2.2$ to $M_{L}=2.9$ events just south of the jog. This activity was followed by about $30 \mathrm{~min}$ of quiescence.

The lull in activity was interrupted by three events (group 3 ) that occurred over a 23 minute time span. These events were scattered around the periphery of the group 2 activity. After these two clusters of activity, there were about 2.5 hours of quiescence at the $M \geq 2.0$ level. Then, approximately 2.3 hours before the $M_{W}=4.4$ immediate foreshock, a series of five events occurred, extending the sequence farther south from the jog (group 4). This was followed by about 1 hour of quiescence, three events in the jog (group 5), nearly another hour of quiescence, and then, in a 20 min period, the last three foreshocks (group 6) including the $M_{W}=4.4$ immediate foreshock.

\section{Static Stress Changes}

We used a dislocation modeling program [Erickson, 1987] to model the stress change expected on the foreshock fault planes due to the previous foreshocks in the sequence. We performed these calculations using only foreshocks with $M_{L}>2.6$. These larger events have better constrained locations and larger source dimensions, so the Coulomb stress change results are less sensitive to location errors. We modeled each foreshock as a circular fault with radius given by equation 2 and displacement of a constant stress drop shear crack [Keilis-Borok, 1959]

$$
\Delta u(r)=\frac{24}{7 \pi} \sqrt{a^{2}-r^{2}} .
$$

Here $a$ is the radius of the fault, and $r$ is the point at which slip is evaluated. All the foreshocks were modeled as vertical strike-slip earthquakes with strike direction based on the focal mechanism for that event. The fault plane for each foreshock was discretized on a $21 \times 21$ grid with displacement on each element scaled according to the relation given above. The stress tensor due to the cumulative dislocation of the preceding events was calculated on a 21×21 grid superimposed on each foreshock fault plane, and at each grid point, the shear tractions resolved in the direction of slip and normal to the fault plane were determined from the stress tensor after Beroza and Zoback [1993]. From these we calculated a Coulomb failure criterion

$$
F=\tau_{s}-\mu_{0} \sigma_{n} .
$$

Here $\tau_{s}$ is the shear traction increase, $\sigma_{n}$ is the normal stress increase, and $\mu_{0}$ is the coefficient of friction. $F$ values greater than zero imply that the fault is moved closer to failure by the change in stress. On the basis of the stress drop estimates of a previous section, we decided to model the static stress changes using uniform stress drops of 1 and $3 \mathrm{MPa}$. The average values are presented in Table 3. Notice that of the nine events analyzed, seven of the foreshocks (for both the 1 and $3 \mathrm{MPa}$ cases) slipped in the opposite direction to the cumulative shear traction change on the fault plane. Of the two foreshocks with a shear traction increase in the direction of slip, one had an increase of less than $0.001 \mathrm{MPa}$.

The Coulomb failure criterion results follow the shear traction results. For both the 1 and $3 \mathrm{MPa}$ stress-drop cases, six foreshocks out of nine had a negative $F$ value and one had an increase in $F$ of less than $0.001 \mathrm{MPa}$. These results are not surprising, given the geometry of the sequence. Crack models predict a decrease in shear stress to the side of a crack within a distance of one crack length after shear failure [Das and Scholz, 1982]. Event 6 is subparallel and immediately adjacent to event 5. Event 10 is parallel and adjacent to both events 5 and 6 . Event 11 is in the shear stress-decrease zone of event 10 , event 25 overlaps event 8 , and so on.

These results suggest that stress transfer from earlier events in the foreshock sequence was not important in triggering the larger foreshocks, although it is possible that adjustment of the foreshock locations and focal mechanisms within their confidence limits could change this conclusion in some cases.

The results for event 25 , the immediate foreshock $\left(M_{w}=4.4\right)$ are much more definite. In this instance the location errors are much smaller than the size of the fault plane $(860$ to $1300 \mathrm{~m}$ in radius depending on the stress drop). The shear and normal traction changes on the fault plane of event 25 are dominated by the effects from the largest foreshock (event 8 in Figure 10), but the trend for all events is to decrease the shear traction in the direction of slip and to decrease the Coulomb failure criterion. These results are unlikely to be changed by adjustment of the foreshock locations within their error bounds, since the bounds are about an order of magnitude smaller than the size of the fault plane for event 25 . 

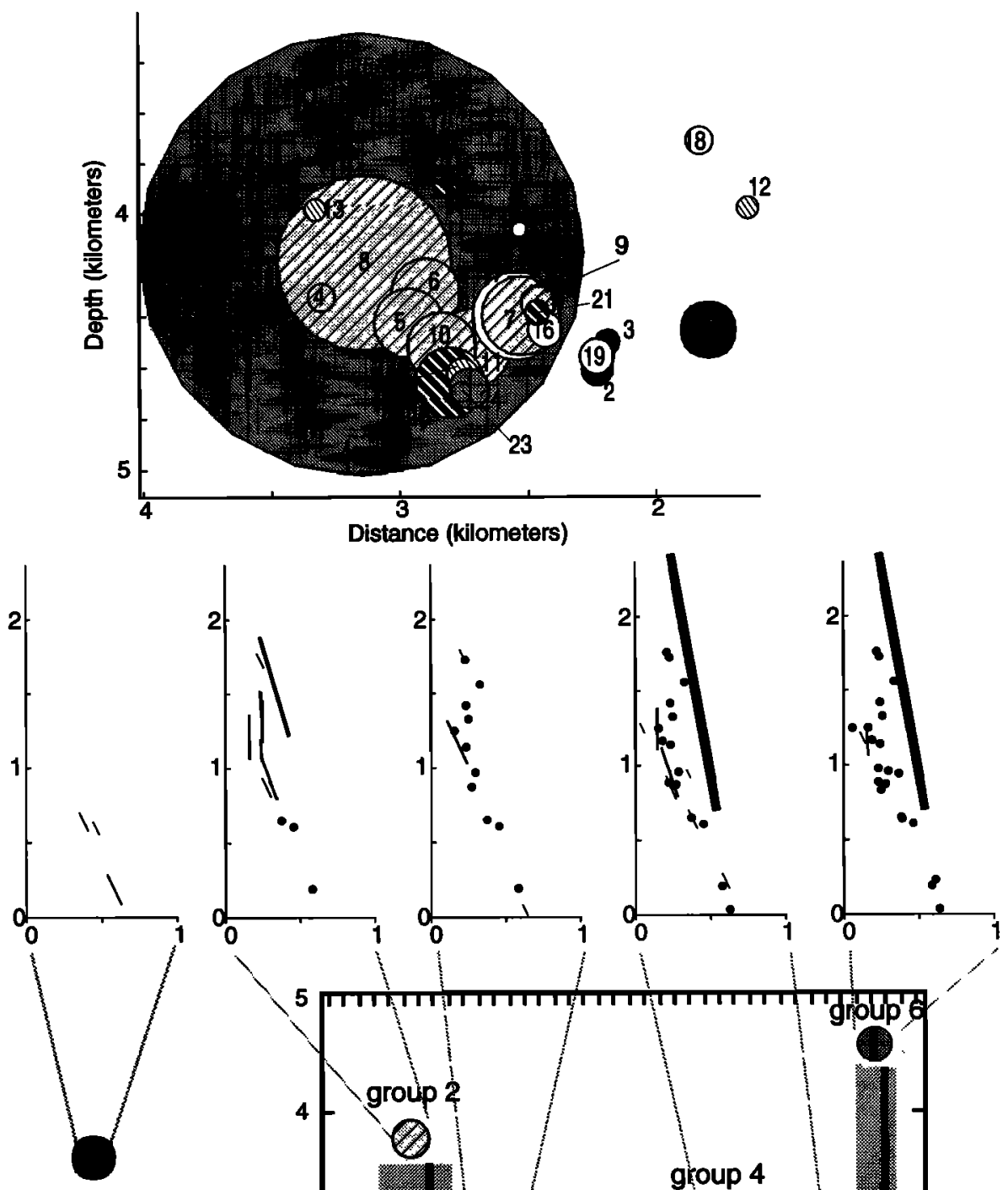

group 1 foreshocks prior to June 28

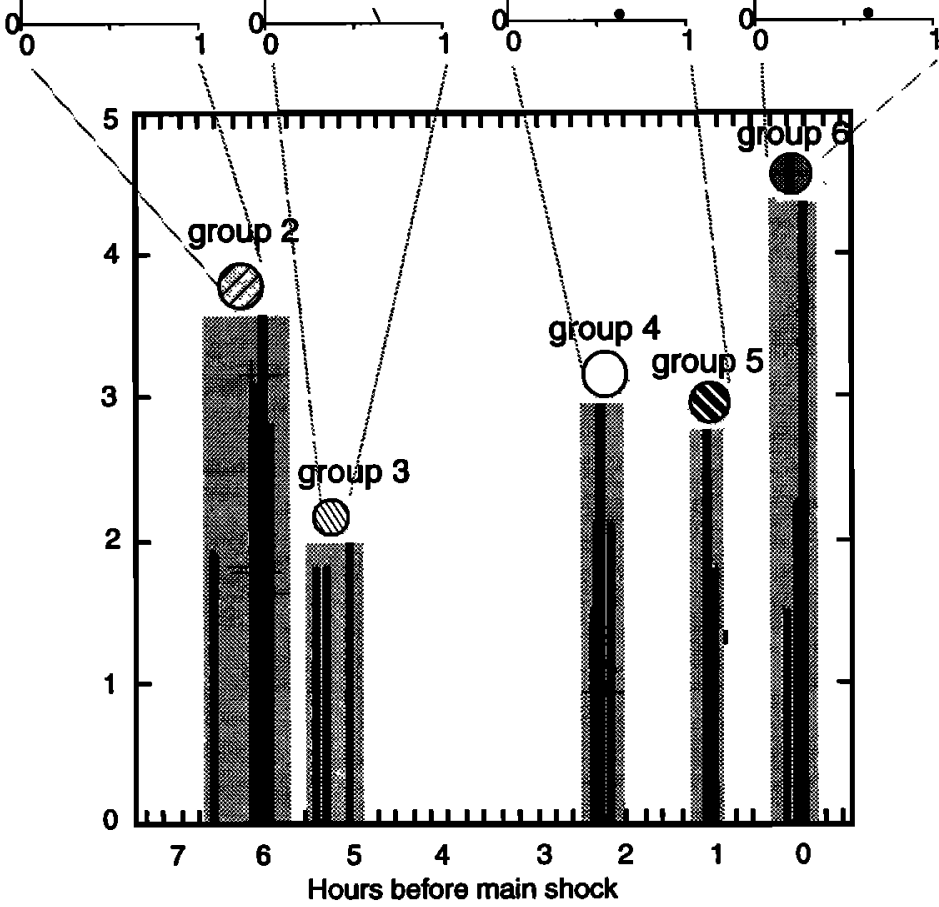

Figure 9. Spatial and temporal distribution of foreshocks. (top) The foreshocks projected onto a north-south plane are shown. Event dimensions are based on a 3 MPa stress drop. The shading pattern of the events corresponds to the bottom key . (middle) Map views of the foreshocks for the time intervals defined. Foreshocks that occur in a given time frame are shown as bars with lengths scaled to the source dimensions of the foreshocks and with orientations equal to the inferred or measured strikes of the events. Foreshocks that occurred in previous time frames are shown as dots. (bottom) The temporal distribution of events in the 7 hours preceding the mainshock. 
Table 3. Resolved Stress Increase on Foreshock Fault Planes

\begin{tabular}{|c|c|c|c|c|c|c|c|}
\hline \multirow[b]{2}{*}{ Event } & \multirow[b]{2}{*}{ Magnitude. } & \multicolumn{3}{|c|}{ 1-MPa Stress Drop } & \multicolumn{3}{|c|}{ 3-MPa Stress Drop } \\
\hline & & $\tau_{s}$ & $\sigma_{n}$ & $\boldsymbol{F}$ & $\tau_{s}$ & $\sigma_{n}$ & $F$ \\
\hline 5 & 2.80 & 0.0007 & 0.0002 & 0.0009 & 0.0007 & 0.0002 & 0.0009 \\
\hline 6 & 2.80 & -0.0262 & 0.1345 & 0.0545 & -0.2165 & 0.0120 & -0.2093 \\
\hline 7 & 2.90 & 0.0322 & -0.0156 & 0.0228 & 0.0795 & -0.0541 & 0.0470 \\
\hline 8 & 3.60 & -0.0313 & 0.0221 & -0.0180 & -0.0484 & 0.0506 & -0.0181 \\
\hline 10 & 2.80 & -0.2873 & 0.1365 & -0.2054 & -0.2378 & 0.5030 & 0.0640 \\
\hline 11 & 2.90 & -0.3709 & 0.4378 & -0.1083 & -0.4767 & 0.5168 & -0.1666 \\
\hline 17 & 3.00 & -0.4601 & 0.2704 & -0.2979 & -0.6562 & 0.1101 & -0.5902 \\
\hline 20 & 2.80 & -0.3523 & -0.0973 & -0.4107 & -0.3111 & 0.0094 & -0.3055 \\
\hline 25 & 4.40 & -0.0393 & 0.0095 & -0.0336 & -0.0716 & -0.0023 & -0.0730 \\
\hline
\end{tabular}

Here $\tau_{s}$ is the shear traction increase, $\sigma_{\text {s }}$ is the normal traction increase, and $F$ is the Coulomb stress for a coefficient of friction of 0.6 .

Although there was a net decrease in Coulomb stress on the fault plane of event 25 , there were local regions of stress increase. It is possible that rupture could have initiated in one of these regions of stress increase. Although this scenario cannot be dismissed, we think it is unlikely since, for the most part, the regions of stress increase are outside the $2 \sigma$ confidence limits for the immediate foreshock hypocenter location (Figure 11).

\section{Discussion}

It is interesting to compare our observations of the Landers sequence with models of foreshock generation. Jones [1984] proposed a model in which a population of asperities fail by delayed multiple rupture. In this model the failure of each asperity causes additional stress to be applied to neighboring asperities, which then fail by static fatigue. If this model is applicable, then there should be a net shear stress increase on each foreshock fault plane prior to the occurrence of that event. Our results suggest that the foreshocks did not, in general, trigger each other. Although some of the smaller foreshocks may have been triggered by their immediate predecessors, most of the large foreshocks, for which the uncertainties in location are small, relative to the rupture dimension, either have negative Coulomb stress changes or very small positive changes. In particular, the $M_{W}=4.4$ immediate foreshock rupture plane is almost certain tc have been destressed by the foreshocks that preceded it. It is worth noting that, had the foreshocks all occurred on a single plane with similar slip directions, they would have acted to trigger each other. It is the three dimensionality of the sequence that allows us to infer another process is operating.

If the foreshocks did not trigger each other, then they must have occurred in response to something else. One possibility is that the nucleation region was weakened by fluid flow [Sibson, 1992]. Another possible mechanism is loading by aseismic creep

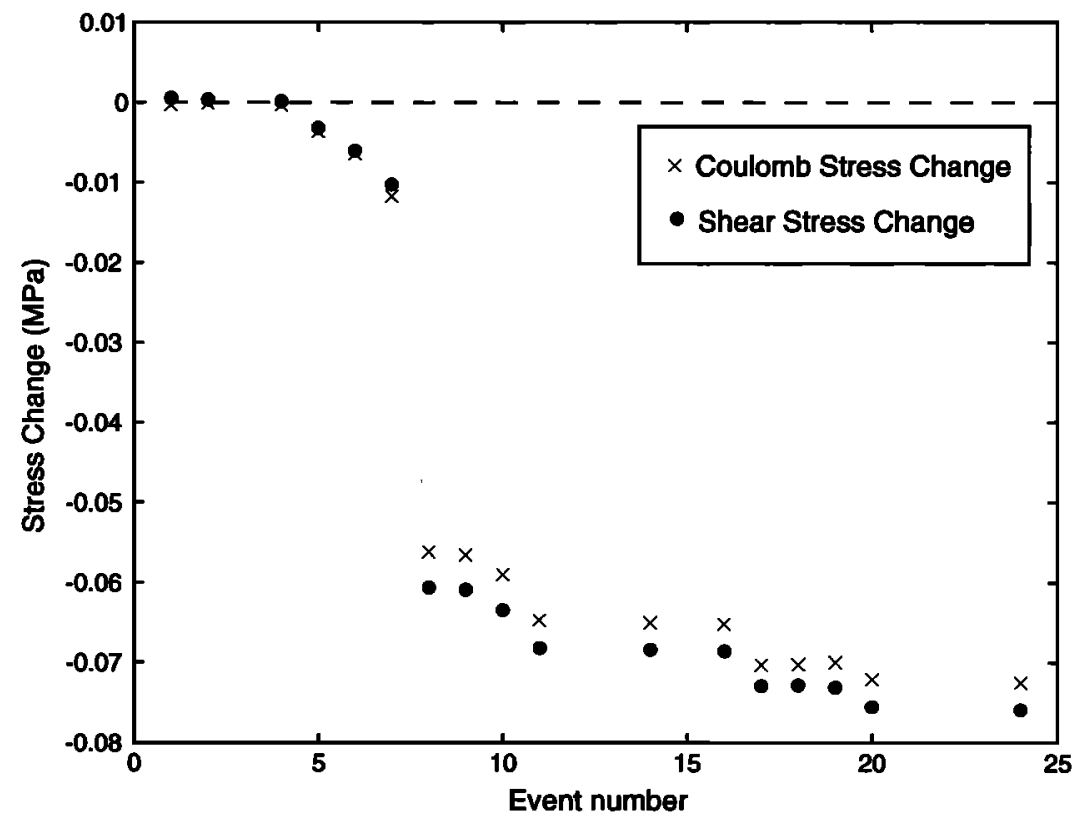

Figure 10. Cumulative change on the $M_{W}=4.4$ immediate foreshock fault plane. Stresses are calculated assuming a $3 \mathrm{MPa}$ stress drop for all events and using only events with $M_{L}>2.6$. The values shown on the plot are the median of the cumulative stress at each time step. The solid circles show the shear traction change in the direction of slip, and the crosses show the Coulomb stress change calculated assuming a coefficient of friction of 0.6 . This shows that the foreshocks are driving the mainshock hypocenter further from failure. 

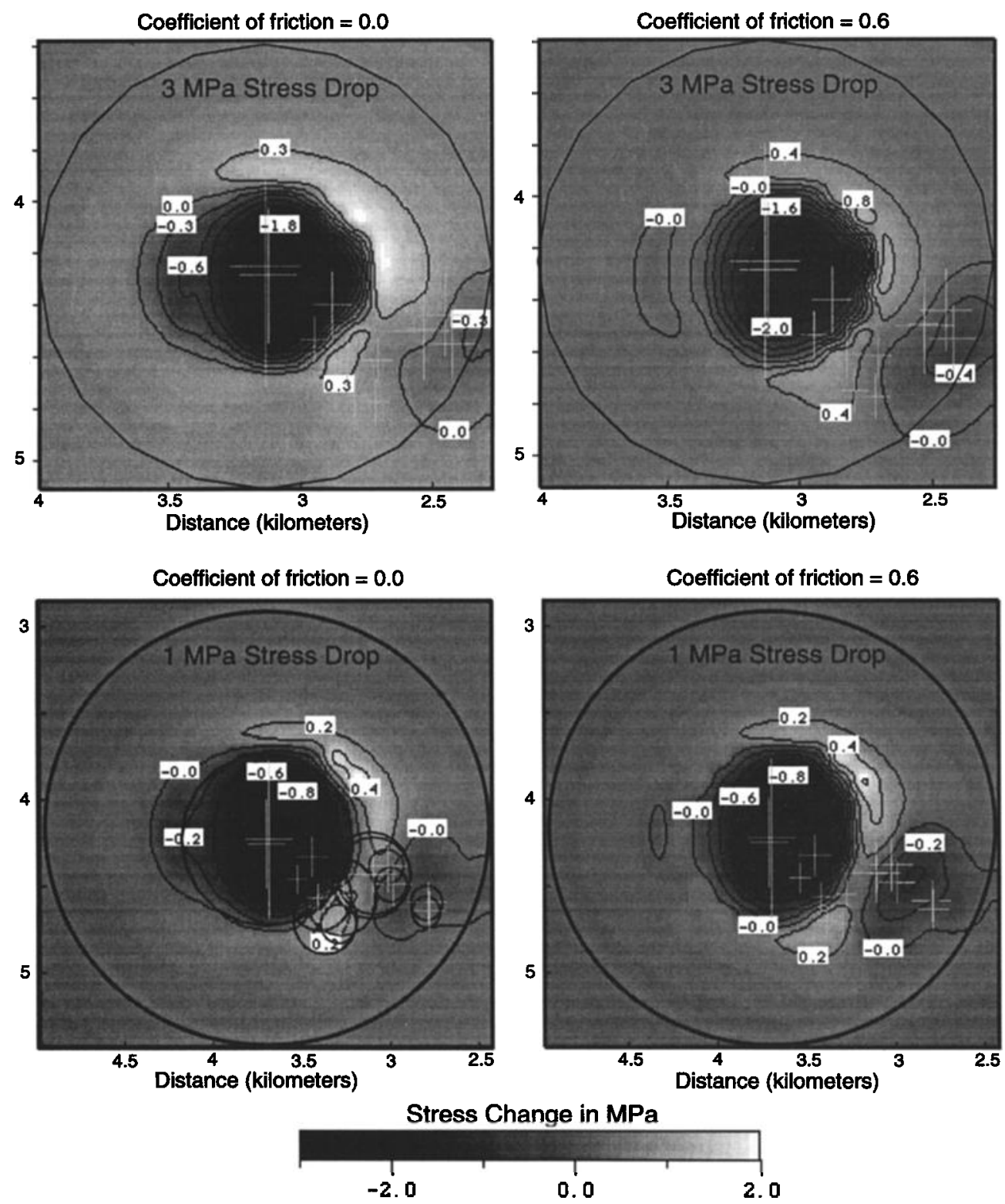

Figure 11. Stress change on the $M_{w}=4.4$ immediate foreshock fault plane. (top) The Coulomb stress change calculated assuming a $3 \mathrm{MPa}$ stress drop for all foreshocks. (bottom) The Coulomb stress change calculated assuming a $1 \mathrm{MPa}$ stress drop. (left) The Coulomb stress change calculated assuming a zero coefficient of friction is shown. (right) The Coulomb stress change calculated assuming a 0.6 coefficient of friction is shown. The crosses show the $2 \sigma$ limits for the foreshock hypocenter locations. All distances are in kilometers.

over the nucleation region. Aseismic creep during the nucleation process is predicted by several models of earthquake nucleation [Dieterich, 1992; Ohnaka, 1992]. The behavior of the Landers foreshock sequence (growth with time, size of region) may provide important constraints on these models.

The geometry of the foreshocks and their focal mechanisms is consistent with right-lateral creep having occurred on the two fault segments bounding the jog. Segall and Pollard [1980] showed that right-lateral earthquakes occurring within a dilatational jog should have a clockwise rotation of focal mechanisms due to the local perturbation to the stress field from slip on the adjacent fault segments. The first events of the immediate foreshock sequence (group 2) occurred in the jog and were rotated clockwise relative to the strike of the seismicity outside the jog. If the rotations are due to a local stress perturbation, then there must have been some slip north and south of the jog prior to the foreshock activity. A search of the SCSN catalog from 1981 revealed just two events of $M_{L}>2.5$ within 2 $\mathrm{km}$ of the jog, and both of those were to the southeast and nearly $2 \mathrm{~km}$ distant. Thus the loading of the jog, if it occurred within the 11 years prior to the Landers earthquake, is likely to have been by aseismic creep. An alternative explanation is that the focal mechanisms are controlled by preexisting fault geometry.

Ohnaka [1992] has proposed a theory of foreshock generation in which foreshocks result from failure of asperities loaded by accelerating premonitory creep. In this model, earthquake nucleation begins at a point on the fault where resistance to rupture growth is a minimum. Quasistatic creep begins there and 
grows outward until a critical dimension is achieved at which point resistance to further growth is exceeded by the stress change, and dynamic instability begins. In this model, foreshocks occur at asperities within the nucleation zone, and as the nucleation zone grows with time, the zone of foreshocks may also grow.

The Landers foreshocks were concentrated within a releasing fault jog, a weak point on the fault because of reduced normal stress. In this respect they are consistent with the Ohnaka model. If it is true that they were driven by aseismic creep, then this is also consistent with Ohnaka's model. However, there are notable inconsistencies between our observations and the behavior this model predicts. For instance, the group 1 events occurred near the southern end of the foreshock zone, yet they were the first events of the extended foreshock sequence. This is inconsistent with a model in which creep nucleates at the fault jog and expands from there. We could argue that since the group 1 events occurred days before the mainshock, they are not genetically related to the rest of the foreshocks. However, they occurred on the same fault plane as most of the other foreshocks, and foreshock number 12 actually occurred south of foreshock number 1 , so it seems likely that the group 1 events were part of the nucleation process. Group 1 events aside, there is still very little indication that the zone of foreshocks expanded with time as predicted by the Ohnaka [1992] model. The group 2 events, which started the immediate foreshock sequence, span an area (in profile) that is over half that spanned by the entire sequence. In other words, the foreshock zone either did not grow significantly with time as required by the Ohnaka model, or else it expanded aseismically. These inconsistencies may reflect the difficulty of applying a twodimensional theory of nucleation to a fault with threedimensional geometry.

Other earthquakes have been observed to nucleate on or near a geometric complexity of a fault. For instance, Bakun et al. [1980] gave several examples of central California earthquakes which nucleated near fault bends. Jones et al. [1982] concluded that the 1975 Haicheng $\left(M_{L}=7.3\right)$ earthquake probably nucleated at an en echelon fault step. Jones [1984] showed that of seven California earthquakes with foreshock sequences, four of the earthquakes were associated with fault zone discontinuities, and the other three were possibly associated with fault zone discontinuities. Lindh et al. [1978] observed a change in the ratios of $P$ wave amplitudes to $S$ wave amplitudes between foreshocks and aftershocks for three California earthquakes, which they attributed to a systematic change in stress or fault orientation in the source region.

Our results for the Landers foreshocks and results from the studies cited above suggest that fault zone geometry can be an essential factor in earthquake nucleation. Such geometry can be easily missed, if the size of the irregularity is less than the uncertainties in the hypocenter locations. More high-resolution studies of foreshock sequences should reveal if rupture nucleation is commonly associated with fault zone discontinuities. If earthquakes often nucleate at strength heterogeneities, then it may be necessary to include the effects of three-dimensional fault structure in realistic models of earthquake nucleation.

\section{Summary}

We have relocated 24 foreshocks and the immediate foreshock to the 1992 Landers $M_{w}=7.3$ earthquake using $P$ and $S$ wave picks determined by waveform cross correlation. The relative event locations have $2 \sigma$ uncertainties which are less than $100 \mathrm{~m}$ horizontally and $200 \mathrm{~m}$ vertically for most events. The relative locations clearly define a near-vertical fault striking approximately $330^{\circ}$ with a right step of about $500 \mathrm{~m}$. The geometry derives independent support from focal mechanisms determined for 15 of the largest events. All focal mechanisms are predominantly right-lateral strikeslip on vertical planes with strikes that follow the trend of the seismicity. Within the jog, the focal mechanisms rotate clockwise, which is consistent with the expected rotation of the stress field for a right-stepping jog on a right-lateral fault [Segall and Pollard, 1980]. Stress drops were determined for six events in or near the jog, and these are all of the order of 1.0 MPa. The immediate foreshock sequence is discontinuous with five distinct temporal clusters and one quiescent period of about 2.5 hours. The first two of these clusters results from the failure of the jog, and the third from extension of the sequence along the southem segment. The final two clusters, which include the $M_{w}=4.4$ immediate foreshock to the mainshock, show no systematic relation to the previous seismicity. Modeling of the Coulomb stress change caused by previous foreshocks resolved on the foreshock fault planes suggests that the sequence was not driven by the stress changes caused by the foreshocks alone. We suggest that the foreshock sequence may have been driven by aseismic creep over the nucleation zone, which is at least as large as the foreshock zone, and that the foreshocks themselves punctuate this larger process. The close association of the Landers foreshocks with the jog in the Johnson Valley fault indicates that the jog may have strongly influenced the nucleation process. If future high-resolution studies of foreshock sequences show that geometric complexities are involved, then it may be necessary to include such complexities in models of rupture nucleation.

Acknowledgments. In this study we used data recorded by the Southem California Seismic Network (SCSN) which is operated jointly by the Seismological Laboratory at Caltech and the U.S. Geological Survey, Pasadena. This manuscript was greatly improved by the careful reviews of Brian Cohee, David Oppenheimer, Martha Savage, Susan Hough, and an anonymous reviewer.

\section{References}

Abercrombie, R., and J. Mori, Local observations of the onset of a large earthquake: 28 June 1992 Landers, California, Bull. Seismol. Soc. Am., 84,725-734, 1994.

Bakun, W.H., R.M. Stewart, C.G. Bufe, and S.M. Marks, Implication of seismicity for failure of a section of the San Andreas fault, Bull. Seismol. Soc. Am., 70, 1185-201, 1980.

Behr, J., R. Bilham, P. Bodin, and S. Gross, Eureka Peak fault afterslip following the 28 June 1992 Landers earthquake, Bull. Seismol. Soc. Am. 84, 826-834, 1994.

Beroza, G.C., and M.D. Zoback, Mechanism diversity of the Loma Prieta aftershocks and the mechanics of mainshock-aftershock interaction, Science, 259, 210-213, 1993.

Boatwright, J., A spectral theory for circular seismic sources: Simple estimates of source dimension, dynamic stress drops, and radiated energy, Bull. Seismol. Soc. Am., 70, 1-28,1980.

Bortugno, E.J., Map showing recency of faulting, San Bernardino quadrangle, California, scale 1:250,000, regional geologic map series, Div. of Mines and Geol., Sacramento, Calif., 1986.

Brune, J. N., Tectonic stress and the spectra of seismic shearwaves from earthquakes, J. Geophys. Res., 75, 4997-5009, 1970.

Cohee, B. P., and G. C. Beroza, Slip distribution of the 1992 Landers earthquake and its implications for earthquake source mechanics, Bull. Seismol. Soc. Am. 84, 692-712, 1994.

Das, S. and C. Scholz, Off-fault aftershock clusters caused by shear stress increase? Bull. Seismol. Soc. Am. 71, 1669-1675, 1982.

Deichmann, N., and M. Garcia-Fermandez, Rupture geometry from highprecision relative hypocentre locations of microearthquake clusters, Geophys. J. Int., 110, 501-517, 1992. 
Dieterich, J.H., Time-dependent friction and the mechanics of stick-slip. Pure Appl. Geophys., 116, 790-806, 1978.

Dieterich, J.H., Earthquake nucleation on faults with rate- and statedependent strength, Tectonophysics, 211, 115-134, 1992.

Dodge, D. A., G.C. Beroza, W.L. Ellsworth, and A.T. Cole, Array analysis of micro-earthquakes to determine the cause of velocity changes associated with the 1989 Loma Prieta earthquake, Seismol. Res. Lett., 64, 33, 1993.

Ellsworth, W.L., Three-dimensional structure of the crust and mantle beneath the island of Hawaii, 327 p., Ph.D. thesis, Mass. Inst. of Technol., Cambridge, 1977.

Erickson, L., User's Manual For DIS3D: A Three-Dimensional Dislocation Program With Applications to Faulting in the Earth, Geomechanics, Applied Earth Science Department, Stanford University, Stanford, Calif., 1987.

Frankel, A., and H. Kanamori, Determination of rupture duration and stress drop from earthquakes in southern California, Bull. Seismol. Soc. Am. 73, 1527-1551, 1983.

Fremont, M., and S.D. Malone, High precision relative locations of earthquakes at Mount St. Helens, Washington, J. Geophys. Res., 92, 10,223-10,236, 1987.

Hauksson, E., L. M. Jones, K. Hutton, and D. Eberhart-Phillips, The 1992 Landers earthquake sequence: Seismological observations, $J$. Geophys. Res., 98, 19,835-19,858, 1994.

Hough, S.E., Southern surface rupture associated with the M 7.31992 Landers, California, earthquake, Bull. Seismol. Soc. Am. 84, 817-825, 1994.

Ishida, M. and H. Kanamori, The foreshock activity of the 1971 San Fernando earthquake, California, Bull. Seismol. Soc. Am. 68, 1265$1279,1978$.

Jones, L. M., Foreshocks (1966-1980) in the San Andreas system, California, Bull. Seismol. Soc. Am. 74, 1361-1380, 1984.

Jones, L. M., and P. Molnar, Some characteristics of foreshocks and their possible relationship to earthquake prediction and premonitory slip on faults, J. Geophys. Res., 84, 3596-3608, 1979.

Jones, L. M., B. Wang, S. Xu, and T. J. Fitch, The foreshock sequence of the February 4, 1975, Haicheng earthquake $(M=7.3)$, J. Geophys. Res., 87, 4575-4584, 1982.

Kanamori, $H$. , The nature of seismicity patterns before large earthquakes, in Earthquake Prediction: An International Review, Maurice Ewing Ser., vol. 4, edited by D. W. Simpson and P. G. Richards, pp. 1-19, AGU, Washington, D. C., 1981

Keilis-Borok, V. I., On the estimation of the displacement in an earthquake source and of source dimensions, Ann. Geofis., 12, 205$214,1959$.
King, G.C.P., R.S. Stein, and J. Lin, Static stress changes and the triggering of earthquakes. Bull. Seismol. Soc. Am. 84, 935-953, 1994.

Lindh, A., G. Fuis, and C. Mantis, Seismic amplitude measurements suggest foreshocks have different focal mechanisms than aftershocks, Science, 201, 56-59, 1978.

Mogi, K., Earthquake Prediction, Academic, San Diego, Calif., 1985.

Mori J., and A. Frankel, Source parameters for small events associated with the North Palm Springs, California, earthquake determined using empirical Green functions. Bull. Seismol. Soc. Am. 80, 278-295, 1990.

Mueller, C. S., Source pulse enhancement by deconvolution of an empirical Green's function, Geophys. Res. Lett., 22, 33-36, 1985.

Ohnaka, M., Earthquake source nucleation: A physical model for short term precursors. Tectonophysics, 211, 149-178, 1992.

Ohnaka, M., Critical size of the nucleation zone of earthquake rupture inferred from immediate foreshock activity. J. Phys. Earth, 4145 - 56, 1993.

Poupinet, G., W. L. Ellsworth, J. Fréchet, Monitoring velocity variations in the crust using earthquake doublets: An application to the Calaveras fault, California, J. Geophys. Res., 89, 5719-5731, 1984

Reasenberg, P., and D. Oppenheimer, FPFIT, FPPLOT and FPPAGE Fortran computer programs for calculating and displaying earthquake fault-plane solutions, U.S. Geol. Surv. Open File Rep., 85-739, 109 pp., 1985.

Roecker, S.W., Seismicity and tectonics of the Pamir-Hindu Kush region of central Asia, Ph.D. thesis, 294 p., Mass. Inst. Technol., Cambridge, 1981.

Segall, P., and D. D. Pollard, Mechanics of discontinuous faults. $J$. Geophys. Res., 85, 4337-4350, 1980.

Sibson, R. H., Implications of fault-valve behaviour for rupture nucleation and recurrence, Tectonophysics, 211, 283-293, 1992.

VanDecar, J. C., and R. S. Crosson, Determination of teleseismic relative phase arrival times using multi-channel cross-correlation and least squares, Bull. Seismol. Soc. Am. 80, 150-169, 1990.

Zongjin, M., F. Zhengxiang, Z. Yingzhen, W. Chengmin, Z. Guomin, and L. Defu, Earthquake Prediction, Springer-Verlag, New York, 1990.

G.C. Beroza and D.A. Dodge, Stanford University, Department of Geophysics, Stanford, CA 94305. (e-mail: dodge@pangea.stanford.edu; beroza@pangea.stanford.edu)

W.L. Ellsworth, U.S. Geological Survey, M.S. 977, Menlo Park, CA 94025. (e-mail: ellswrth @andreas.wr.usgs.gov)

(Received July 5, 1994; revised March 9, 1995; accepted March 14, 1995.) 